\title{
Functional Analysis of Four Mutants of the V2 Receptor
}

\section{Beril Erdem $^{1}$, Angela Schulz' ${ }^{2}$ Emel Saglar', Torsten Schöneberg' ${ }^{2}$, Ferhat Deniz ${ }^{3}$, Hatice Mergen ${ }^{1}$}

${ }^{1}$ Hacettepe University, Faculty of Science, Department of Biology, Ankara, Turkey

2 Leipzig University, Faculty of Medicine, Institute of Biochemistry, Leipzig, Saxony, Germany

${ }^{3}$ GATA Haydarpasa Teaching Hospital, Department of Endocrinology and Metabolizm, Istanbul, Turkey
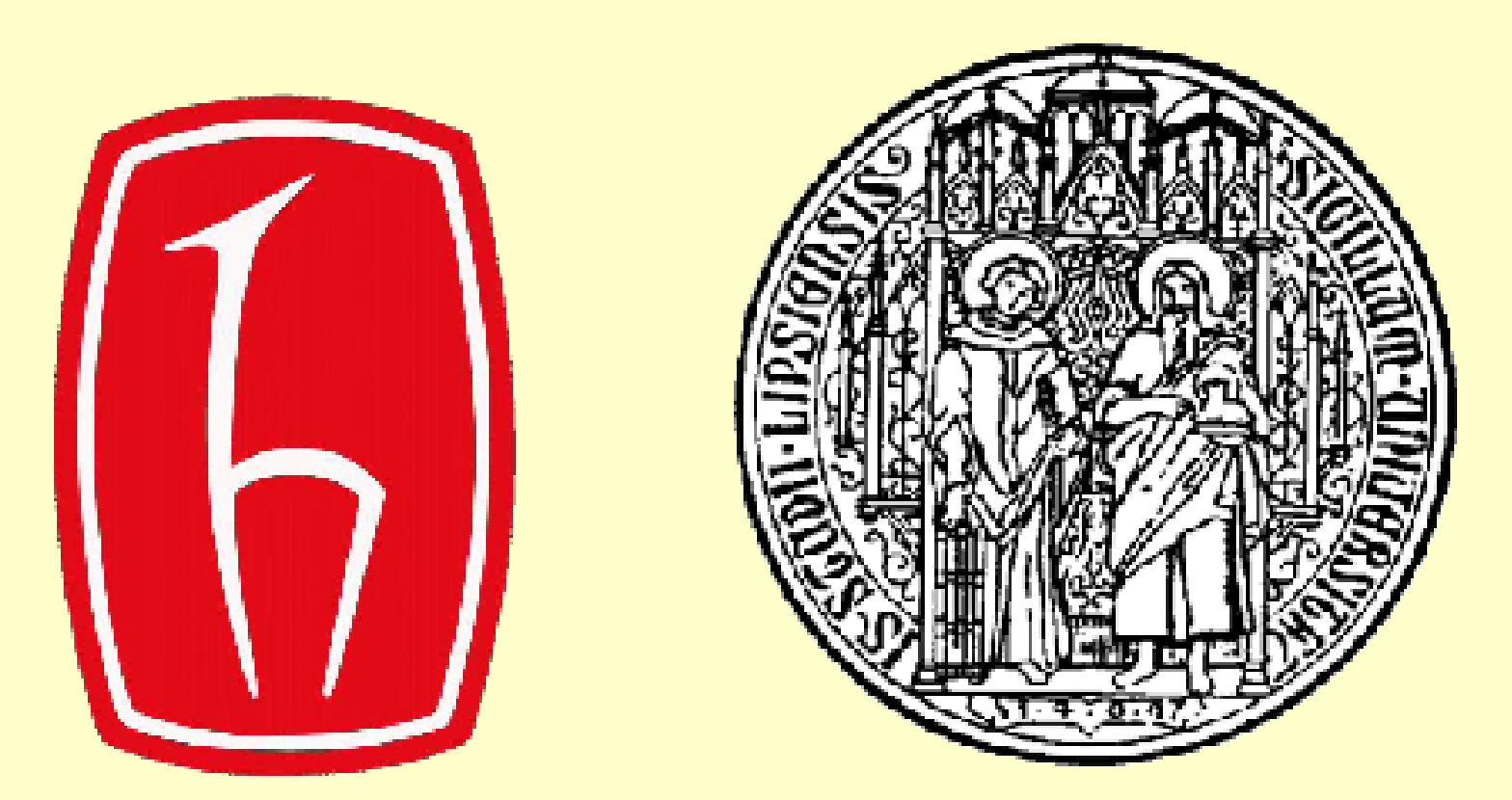

\section{OBJECTIVES}

Diabetes insipidus is a disorder characterized by severe liquidimbalance because of the inability to concentrate urine. Inactivating mutations in either AVPR2 (arginine vasopressin receptor type 2) or AQP2 (aquaporin 2) gene can cause congenital Nephrogenic diabetes insipidus (NDI). AVPR2 is a $G$ protein-coupled receptor (GPCR) and is mainly expressed at the basolateral side of the kidneys collecting duct principal cells. Activation of this receptor by vasopressin is responsible for elevation of cAMP levels resulting in insertion of AQP2 water channels in the cell membrane of the collecting duct cells.

In this study, four new mutations of AVPR2 gene (R68W, R67_G69del/G107W, V162A and T273M) were found in patients and were functionally analyzed.

\section{METHODS}

A pLV2R, a mammalian expression vector containing the entire coding sequence of the human AVPR2, was used to generate all mutants with a PCR-based site-directed mutagenesis and restriction fragment replacement strategy. All constructs were $\mathrm{N}$ - and $\mathrm{C}$-terminal epitopetagged to allow receptor detection by ELISA studies (N-terminal: Haemagglutinin (HA)-tag; Cterminal: FLAG-tag). The correctness of all constructs was confirmed by DNA sequencing.

$72 \mathrm{~h}$ after transfection of COS-7 cells, stimulation with various AVP concentrations ([Arg8]vasopressin acetate salt, Sigma-Aldrich, Seelze, Germany) was performed for $1 \mathrm{~h}$ at $37^{\circ} \mathrm{C}$. The CAMP content of cell extracts was determined by a non-radioactive CAMP accumulation assay based on the ALPHAScreen technology according to the manufacturer's protocol (Perkin Elmer LAS, Rodgau-Jügesheim, Germany).

The cell surface expression of receptors carrying an N-terminal HA-tag was estimated by indirect cellular ELISA. As a further assay to measure the total expression of full-length doubletagged AVPR2s (N-terminal HA-tag, C-terminal FLAG-tag), a sandwich ELISA was used.

Table 1. Clinical features of the patients
\begin{tabular}{|c|c|c|c|c|c|}
\hline Mutations & Sex & $\begin{array}{c}\text { Age } \\
\text { (Years) }\end{array}$ & $\begin{array}{c}\text { Urine osmolality } \\
\left(\text { OOsm/kg } \mathrm{H}_{2} \mathrm{O}\right)\end{array}$ & $\begin{array}{c}\text { Plasma osmolality } \\
\left(\text { (mOsm/kg } \mathrm{H}_{2} \mathrm{O}\right)\end{array}$ & $\begin{array}{c}\text { Urine volume } \\
\text { (Lday) }\end{array}$ \\
\hline R67_R69de/G107W & Male & 20 & 107 & 301 & 12 \\
\hline R68W & Male & 27 & 158 & 299 & 12,5 \\
\hline V162A & Male & 27 & 99 & 302 & 12,1 \\
\hline T273M & Male & 29 & 227 & 316 & 7,8 \\
\hline
\end{tabular}

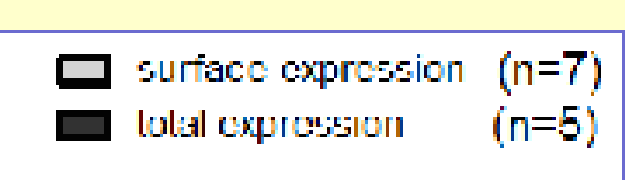

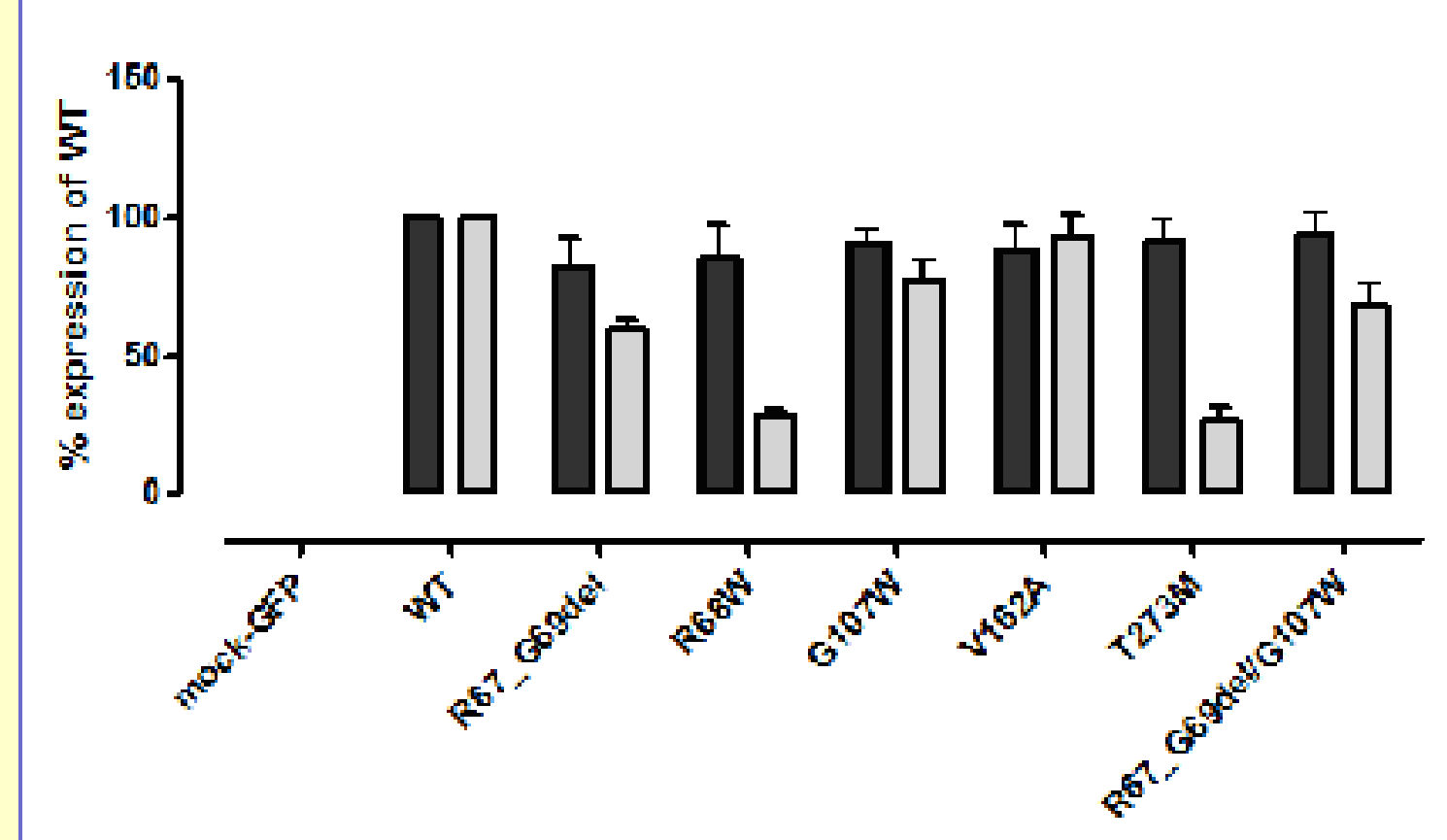

Figure 2. ELISA results of the mutants. WT (Wild type of V2R)
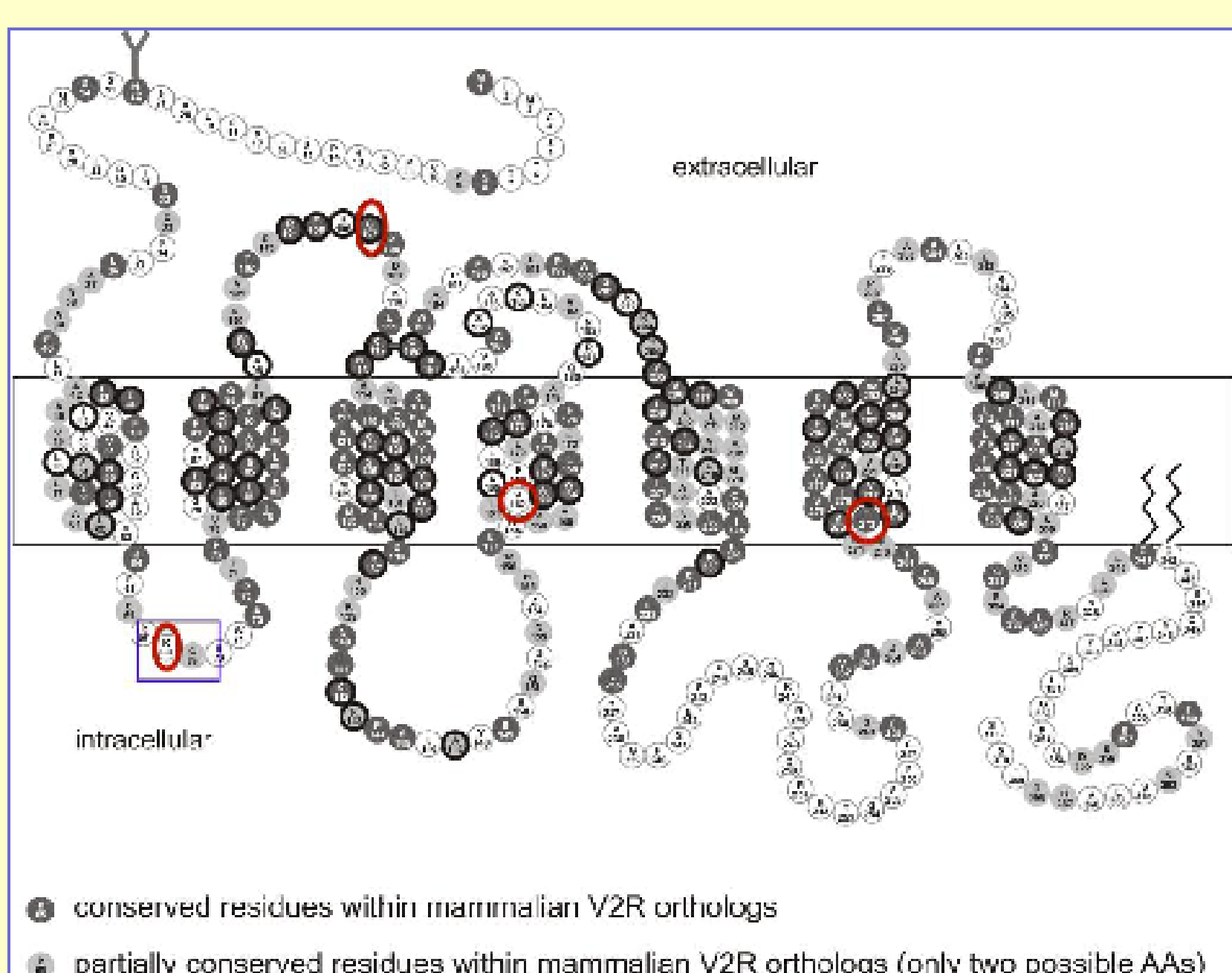

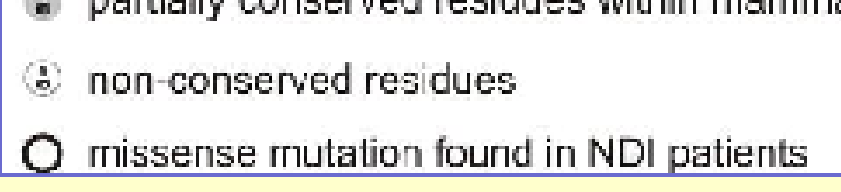

Figure 1. The amino acid sequence of the human V2 receptor (The figure is an excerpt from Böselt et al., 2009). Mutations which were analyzed in this study are
indicates the 9 bp deletion.

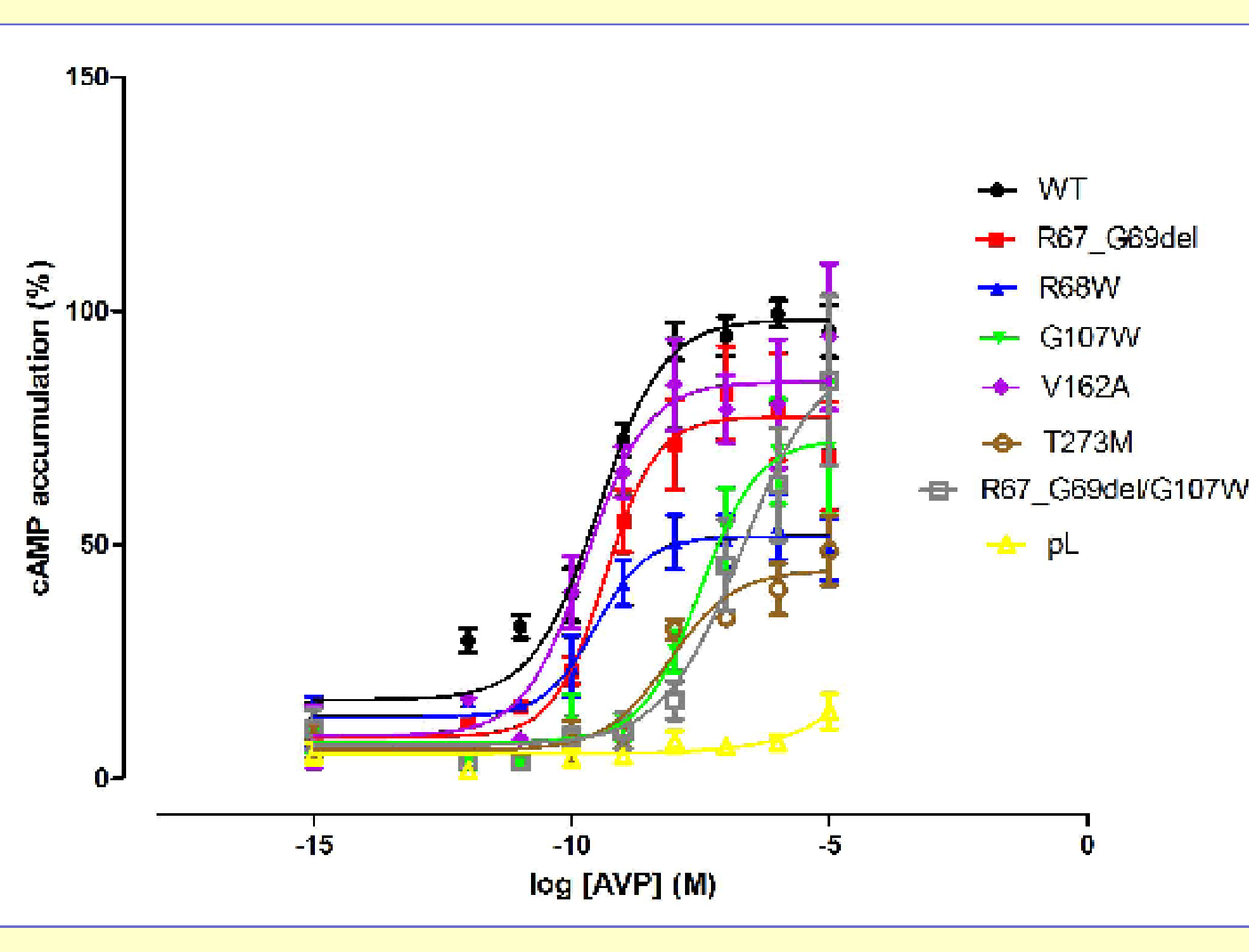

Figure 3. The graph of $\%$ response of the mutations

\section{RESULTS \& CONCLUSIONS}

Five different mutations (Figure 1) were introduced into pLV2R with PCR-based site-directed mutagenesis and restriction fragment replacement method (R68W, R67_G69del/G107W, V162A and T273M). For the R67_G69del/G107W mutation (compound heterozygous), we also introduced and analyzed both mutations (R67_G69del and G107W) separately. The clinical characteristics of the patients who have the mutations are seen in Table 1. All patients show low urine osmolalities and large urine volumes, clearly indicating the symptoms of NDI.

According to total ELISA results (Figure 2), all mutant receptors were synthesized comparable to wild type receptor. However, cell surface expression was impaired for all mutants except of $\mathrm{V} 162 \mathrm{~A}$.

cAMP measurement for mutant and wild type receptors revealed reduced $E_{\max }$ values for all mutants. For some mutants (R68W, R67_G69del/G107W and T273M) concentration response curves showed shifted $\mathrm{EC}_{50}$ values to higher vasopressin concentrations (Figure 3 ).

The in-depth characterization of the receptor function is important for our patients because mutations leading to only a slightly shifted $\mathrm{EC}_{50}$ values by one magnitude could be treated with higher amounts of AVP to reduce high urine volumes and to restore kidney function (R67_G69del/G107W mutant which can be seen on the graph).

In conclusion, we characterized four new AVPR2 mutations found in Turkish patients (TUBITAK SBAG 112S513). Some mutations lead to shifted EC ${ }_{50}$ values by only one magnitude and treatment with higher amounts of AVP could be helpful for these patients to reduce high urine volumes and to restore kidney function.

\section{References}

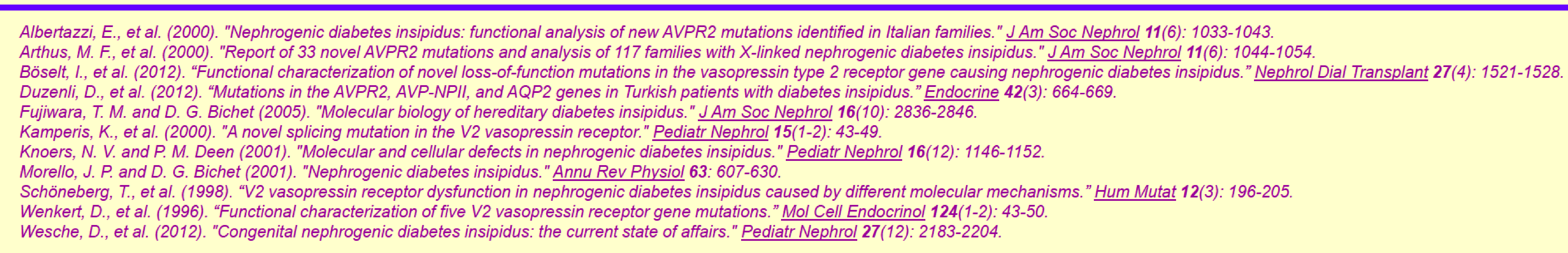

